\title{
Haemophilus influenzae Pyomyositis in a Patient with Diabetic Ketoacidosis: A Unique Case and Review of Literature
}

\author{
Kamolyut Lapumnuaypol, ${ }^{1}$ Sanna Fatima, ${ }^{1}$ Pradhum Ram, ${ }^{1}$ \\ Gemlyn George, ${ }^{1}$ and Antoinette Climaco ${ }^{2}$ \\ ${ }^{1}$ Department of Internal Medicine, Einstein Medical Center, Philadelphia, PA, USA \\ ${ }^{2}$ Department of Infectious Disease, Einstein Medical Center, Philadelphia, PA, USA \\ Correspondence should be addressed to Kamolyut Lapumnuaypol; lapumnuk@einstein.edu
}

Received 12 December 2016; Accepted 6 February 2017; Published 2 March 2017

Academic Editor: Paola Di Carlo

Copyright (C) 2017 Kamolyut Lapumnuaypol et al. This is an open access article distributed under the Creative Commons Attribution License, which permits unrestricted use, distribution, and reproduction in any medium, provided the original work is properly cited.

\begin{abstract}
Haemophilus influenzae is a Gram-negative bacillus commonly known to cause upper respiratory tract infections. Skin and soft tissue infections are very uncommon. Of these, the majority were associated with necrotizing fasciitis requiring emergent debridement. We report a case of pyomyositis caused by Haemophilus influenzae in an adult with diabetes.
\end{abstract}

\section{Introduction}

Haemophilus influenzae is a gram-negative bacillus commonly known to cause upper respiratory tract infections. In the years past, Type b was commonly thought to cause invasive infections, however with increasing vaccinations against the strain, other serotypes particularly type $\mathrm{F}$, have been associated with more recent infections in recent times. Regardless of the strain, skin and soft tissue infections caused by this organism are uncommon and only a handful of cases have ever been reported including both pediatric and adult population [1]. Of these, the majority were associated with necrotizing fasciitis requiring emergent debridement. We present here, a case of pyomyositis caused by nontypeable Haemophilus influenzae in an adult female with diabetes.

\section{Case Presentation}

A 67-year-old female presented to the emergency department with sudden onset of nontraumatic left thigh pain and inability to bear weight for 1 hour. She had a medical history of uncontrolled diabetes mellitus, hypertension, dyslipidemia, and hepatitis $\mathrm{C}$ infection. She denied any injuries or sick contacts at home. On admission, she was noted to be afebrile. On physical examination, the left thigh was noted to be
$6 \mathrm{~cm}$ larger than the right, exquisitely tender with no obvious erythema or warmth. Her movement at the hip joint was limited secondary to pain. Physical examination of the knee joint, calf, and ankles was unremarkable. Neurological exam was normal and distal pulses were palpable.

Routine chemistry and hematology revealed white blood cell count of $12,100 / \mu \mathrm{L}$ (polymorphonuclear cells $78 \%$ with bands $5 \%$ ), platelet count of $54 \times 10^{9} / \mu \mathrm{L}$, C-reactive protein of $197 \mathrm{mg} / \mathrm{L}$ (normal 0-5 mg/L), lactate of $30 \mathrm{mg} / \mathrm{dL}$ (normal $<19 \mathrm{mg} / \mathrm{dL}$ ), and creatine kinase of $59 \mathrm{IU} / \mathrm{L}$ (normal 20$168 \mathrm{IU} / \mathrm{L})$. She also had blood glucose of $558 \mathrm{mg} / \mathrm{dL}$ with anion gap metabolic acidosis (venous $\mathrm{pH}$ of 7.33 anion gap 25) and ketones in the urine. Her clinical presentation was suspicious for a soft tissue infection that likely triggered her DKA. The patient was empirically started on vancomycin, cefepime, and metronidazole. She also received intravenous fluids and intravenous regular insulin infusion for treatment of DKA.

An MRI of left lower extremity was obtained that showed intense edema with fluid tracking along the adductor magnus and quadratus femoris muscle and multiple small rimenhancing fluid collections within the left adductor magnus, which correlated with the site of pain (Figure 1). The largest area of pus collection was $2.9 \times 0.8 \mathrm{~cm}$. Surgery and interventional radiology teams were consulted in an attempt to drain 


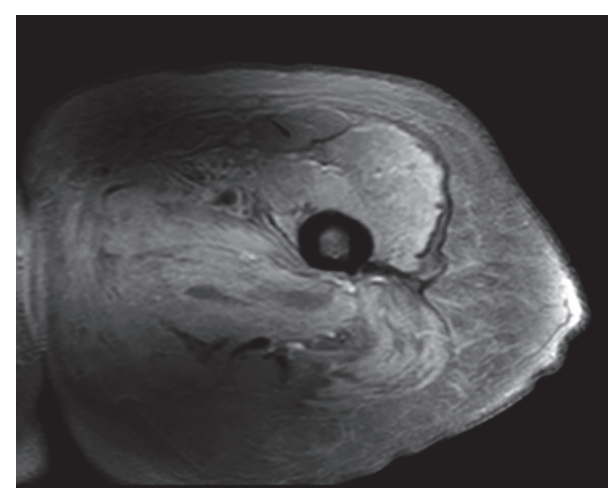

(a)

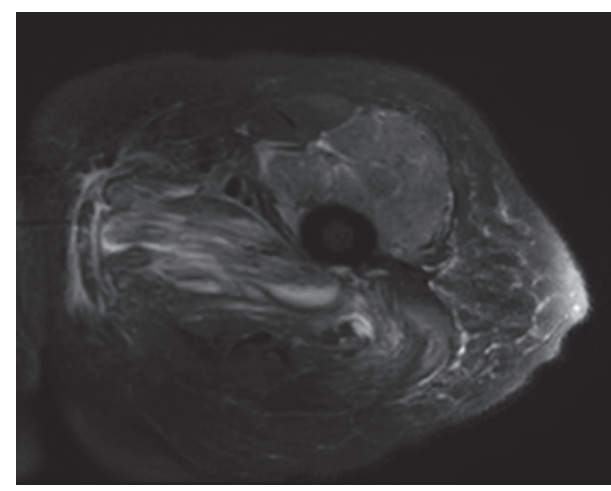

(b)

FIGURE 1: (a) MRI axial T1 with gadolinium, (b) axial T2 without gadolinium showed collection sized $2.9 \times 3 \mathrm{~cm}$ with intramuscular edema.

the collections. Ultrasound of left thigh was performed, but the pus collection was deemed too small to be drained. The blood cultures grew Haemophilus influenzae. The antibiotics were deescalated to ampicillin-sulbactam after the culture results.

The patient was managed with intravenous antibiotics. After 10 days of ampicillin-sulbactam, the patient's pain, swelling, and range of motion improved. C-reactive protein declined gradually from $197 \mathrm{mg} / \mathrm{L}$ to $55 \mathrm{mg} / \mathrm{L}$. Her blood glucose was controlled with long-acting insulin and her platelet count normalized prior to discharge. She was discharged to a skilled nursing facility for physical rehabilitation and was to continue amoxicillin-clavulanate for another 2 weeks. Her follow-up visit with primary care physician at 3 months showed that she could ambulate independently.

\section{Discussion}

Pyomyositis is a suppurative infection of skeletal muscle characterized by collection of pus in individual muscle groups. It usually arises from hematogenous spread of an infective focus. It has traditionally been associated with the tropical climate; nonetheless, it has been recognized in temperate climates as well. Tropical pyomyositis occurs in both children and adults, while the temperate pyomyositis occurs primarily in adults. In the past decade, there is an increasing incidence of pyomyositis in a temperate region among children [2]. Most patients with tropical pyomyositis are otherwise healthy without underlying comorbidities; however, majority of the patients in temperate regions are immunocompromised or have other serious underlying conditions [3].

The risk factors associated with development of pyomyositis include immunodeficiency states comprising HIV, diabetes, malnutrition, organ transplantation, and malignancy [3]. Injection drug use and trauma during exercise are some of the other predisposing factors for development of pyomyositis $[4,5]$. Given that our patient had uncontrolled diabetes, risk of pyomyositis was increased but it is difficult to ascertain if the pyomyositis was responsible for the development of the ketoacidotic state.

More than $90 \%$ of the cases of pyomyositis are caused by $S$. aureus [3]. In a retrospective study of 205 cases in 112 patients with pyomyositis conducted by Chiedozi in Nigeria the most common organism isolated was $S$. aureus followed by $S$. pyogenes [6]. There are very few cases of pyomyositis caused by Gram-negative rods [4, 7-9]. The rare organisms known to cause pyomyositis include Klebsiella pneumoniae, Proteus, and meninogococcus. To our knowledge, only two cases of $H$. influenza causing pyomyositis in adult and one infant have been described in literature $[10,11]$.

The patients with pyomyositis most often present with fever and pain at the site of muscle involvement [3]. According to the severity, pyomyositis can be divided into three stages [3]. Stage 1 (between days 1 and 10) is the invasive stage where muscle cramps and low-grade fever are observed, but other physical findings are typically absent. A "woody texture" of muscle may be noted in this stage. The majority of patients present in stage 2 (10-21 days after initial onset of symptoms). This is also called the suppurative stage with abscess formation. The late stage or stage 3 is potentially fatal and is associated with complications such as rhabdomyolysis, endocarditis, septic shock, brain abscess, and other features of disseminated infection. Treatment depends on the stage of disease [3]. Our patient's presentation was compatible with stage 2 .

Diabetes is a known risk factor for pyomyositis [12]. In our patient diabetic ketoacidosis and severe pain at the site of muscle involvement led to a diagnosis of pyomyositis. The source of our patient's organism (nontypeable $H$. influenzae) remains unclear, especially in the setting of no recent travel, sick contacts including children, or recent upper respiratory tract infection. Nontypeable $H$. influenzae vaccine in adults has been studied and further clinical trial is warranted to explore clinical benefits [13-15].

\section{Conclusion}

Pyomyositis can be potentially fatal if not diagnosed early enough and treated adequately. Here, we managed a unique and rare case of pyomyositis caused by nontypeable Haemophilus influenzae.

\section{Competing Interests}

The authors declare that they have no competing interests. 


\section{References}

[1] M. Stumvoll and A. Fritsche, "Necrotizing fasciitis caused by unencapsulated Haemophilus influenzae," Clinical Infectious Diseases, vol. 25, no. 2, p. 327, 1997.

[2] P. Moriarty, C. Leung, M. Walsh, and C. Nourse, "Increasing pyomyositis presentations among children in Queensland, Australia," Pediatric Infectious Disease Journal, vol. 34, no. 1, pp. 1-4, 2015.

[3] N. F. Crum, "Bacterial pyomyositis in the United States," American Journal of Medicine, vol. 117, no. 6, pp. 420-428, 2004.

[4] M. J. Chusid, W. C. Hill, J. A. Bevan, and J. R. Sty, "Proteus pyomyositis of the piriformis muscle in a swimmer," Clinical Infectious Diseases, vol. 26, no. 1, pp. 194-195, 1998.

[5] R. Jayoussi, V. Bialik, A. Eyal, N. Shehadeh, and A. Etzioni, "Pyomyositis caused by vigorous exercise in a boy," Acta Poediatrica, vol. 84, no. 2, pp. 226-227, 1995.

[6] L. C. Chiedozi, "Pyomyositis. Review of 205 cases in 112 patients," The American Journal of Surgery, vol. 137, no. 2, pp. 255259, 1979.

[7] T. K. Wang, S. S. Wong, and P. C. Woo, "Two cases of pyomyositis caused by Klebsiella pneumoniae and review of the literature," European Journal of Clinical Microbiology and Infectious Diseases, vol. 20, no. 8, pp. 576-580, 2001.

[8] G. F. Falasca and A. J. Reginato, "The spectrum of myositis and rhabdomyolysis associated with bacterial infection," Journal of Rheumatology, vol. 21, no. 10, pp. 1932-1937, 1994.

[9] M. T. Barakat, K. Gajurel, K. Fischer, K. Stevens, E. Ozdalga, and J. G. Montoya, "A case of meningococcal pyomyositis in an otherwise healthy adult," Open Forum Infectious Diseases, vol. 3, no. 3, Article ID ofw087, 2016.

[10] F. Isabel Hidalgo, M. T. Vázquez, E. Portilla, J. López-Anglada, and R. Saavedra, "Pyomyositis caused by Haemophilus influenzae in an immunocompetent adult," Enfermedades Infecciosas y Microbiología Clínica, vol. 15, no. 5, pp. 273-274, 1997.

[11] J. M. Jordan, V. W. Hsu, and N. B. Allen, "Pyomyositis and polyarticular septic arthritis from Hemophilus influenzae in a nonimmunocompromised adult," The Journal of Rheumatology, vol. 14, no. 6, pp. 1190-1192, 1987.

[12] N. Joshi, G. M. Caputo, M. R. Weitekamp, and A. W. Karchmer, "Infections in patients with diabetes mellitus," New England Journal of Medicine, vol. 341, no. 25, pp. 1906-1912, 1999.

[13] G. Leroux-Roels, P. Van Damme, W. Haazen et al., "Phase I, randomized, observer-blind, placebo-controlled studies to evaluate the safety, reactogenicity and immunogenicity of an investigational non-typeable Haemophilus influenzae (NTHi) protein vaccine in adults," Vaccine, vol. 34, no. 27, pp. 3156-3163, 2016.

[14] A. Behrouzi, F. Vaziri, F. Rahimi-Jamnani et al., "Vaccine candidates against nontypeable haemophilus influenzae: a review," Iranian Biomedical Journal, vol. 21, no. 2, pp. 69-76, 2017.

[15] C.-Z. Hua, W.-L. Hu, S.-Q. Shang, J.-P. Li, L.-Q. Hong, and J. Yan, "Serum concentrations of antibodies against outer membrane protein $\mathrm{P} 6$, protein $\mathrm{D}$, and T- and B-cell combined antigenic epitopes of nontypeable Haemophilus influenzae in children and adults of different ages," Clinical and Vaccine Immunology, vol. 23, no. 2, pp. 155-161, 2016. 


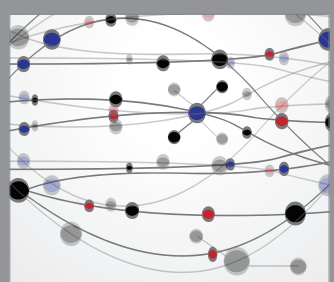

The Scientific World Journal
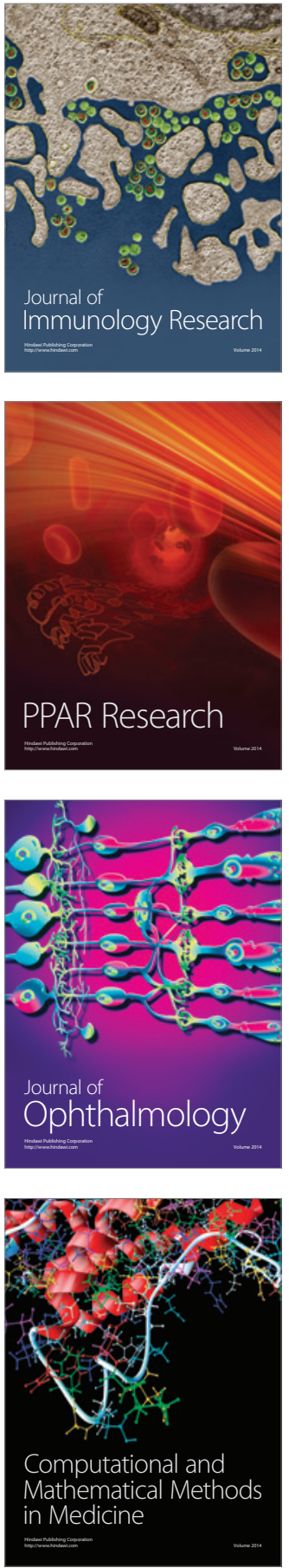

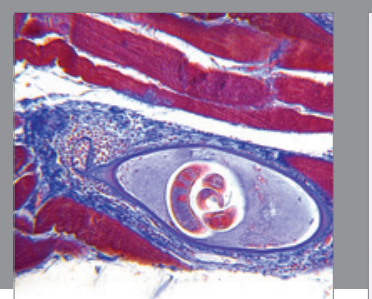

Gastroenterology Research and Practice
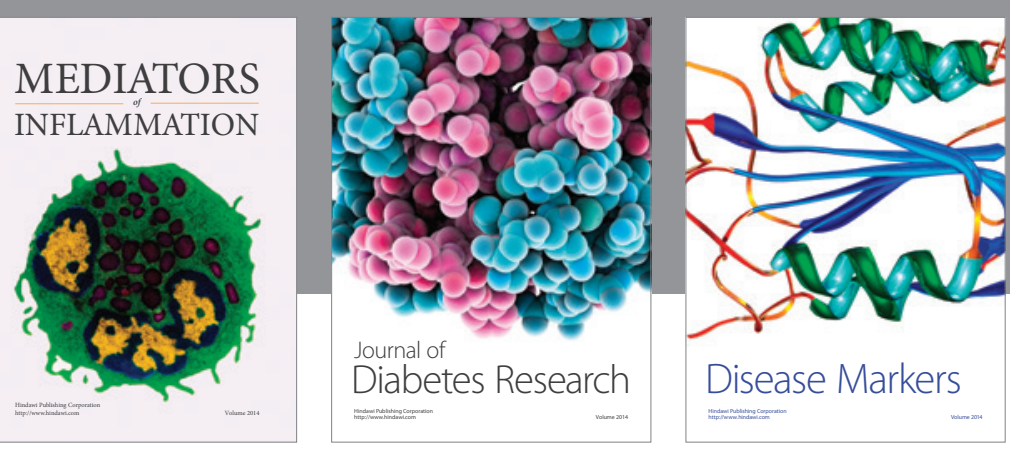

Disease Markers

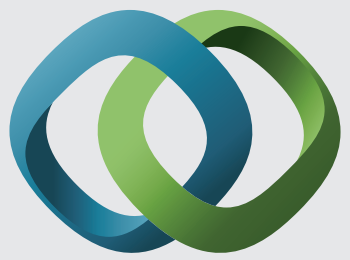

\section{Hindawi}

Submit your manuscripts at

https://www.hindawi.com
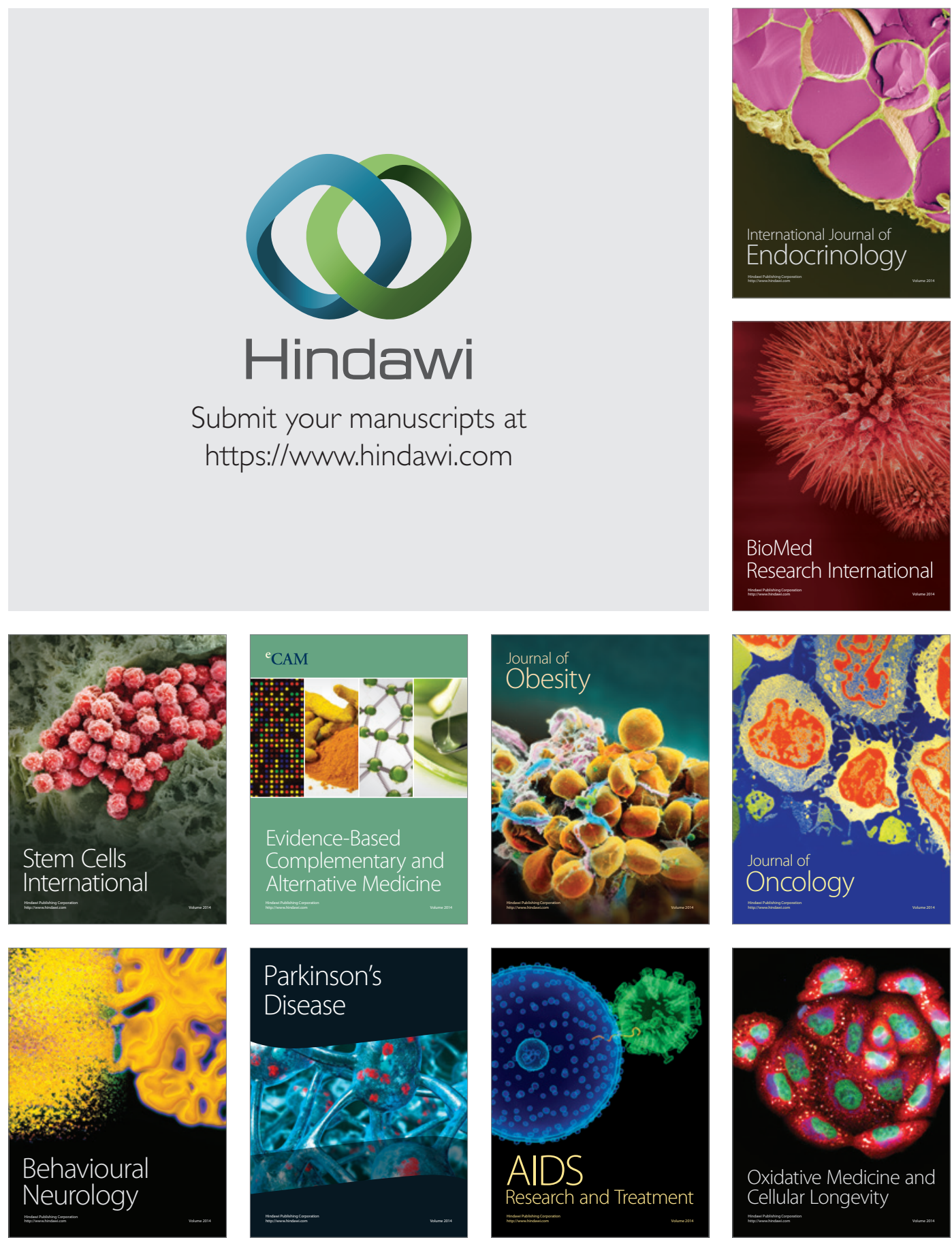